\title{
Process and Outcome
}

\section{Relative costs of home and hospital confinement}

\author{
J A STILWELL
}

British Medical fournal, 1979, 2, 257-259

delivery, and postnatal care of 22 women who booked a home delivery in Dudley in 1977. Their age and gravidity are given in table I. The

\section{Summary and conclusions}

The first study in a series concerned with the costs of different strategies of maternity care showed the differences between the costs of booked confinement at home, in a GP hospital for 48 hours, and in a consultant obstetric unit for 48 hours to be small. The study costed 1977 home confinements in Dudley and compared them with matched samples of hospital births. The factors that compensated, in the home booked deliveries, for the cost of hospital stay were an average of 11 extra visits from community m.idwives, midwife attendance for six hours at delivery, and a proportion who were transferred to hospital after receiving the extra antenatal care of a home booked delivery. This differential transfer rate is a crucial factor that merits further investigation.

Family-borne costs were included in the study. The most significant was time off work by the husband. Average family costs were $£ 68$, about $30 \%$ of public sector costs. Any acceptable strategy of home confinements must provide for last-minute transfers to hospital.

\section{Introduction}

Over the past ten years maternity care has changed considerably. The proportion of babies born at home in England and Wales has fallen from $25^{\circ}{ }_{0}$, to $2 \cdot 5^{\circ}{ }_{0} .^{1}$ The Peel Committee ${ }^{2}$ referred to the "greater safety of hospital confinement for mother and child" and recommended an expansion in hospital maternity services, which has taken place. A recent study ${ }^{3}$ has supported this conclusion, but medical opinion is not unanimous. ${ }^{4-8}$ Moreover, groups exist that lobby, on grounds other than purely medical, in favour of home delivery. The relative costs of home and hospital confinement are clearly germane to this issue. In 1970 Ferster and Pethybridge ${ }^{9}$ concluded that hospital confinements were more expensive. Then, however, the 48-hour discharge system was seldom operated, mean stay being five to six days. The present study was undertaken to estimate the current cost differences between births in a consultant obstetric unit, a GP unit, and at home. Only deliveries expected to be normal were included in the study, since a home booking would not otherwise be considered.

\section{Method}

To isolate the differences between the resources used for home and hospital confinements, a detailed study was made of the antenatal,

Health Services Research Centre, Department of Social Medicine, University of Birmingham, Edgbaston, Birmingham B15 2TJ

J A STILWELL, MA, research fellow

TABLE I-Age and gravidity of the home group

\begin{tabular}{|c|c|c|c|c|c|c|c|}
\hline Age & & $19-21$ & $22-24$ & $25-27$ & $28-30$ & $31-33$ & \\
\hline Gravidity & $\begin{array}{l}1 \\
2 \\
3 \\
4 \\
8\end{array}$ & $\begin{array}{l}\overline{1} \\
3 \\
-\end{array}$ & $\frac{\frac{2}{2}}{1}$ & $\begin{array}{l}1 \\
2 \\
3 \\
\end{array}$ & $\begin{array}{l}\overline{2} \\
4 \\
-\end{array}$ & $\begin{array}{l}\overline{1} \\
\frac{1}{1}\end{array}$ & $\begin{array}{r}1 \\
8 \\
11 \\
1 \\
1\end{array}$ \\
\hline Total & & 4 & 3 & 6 & 6 & 3 & \\
\hline
\end{tabular}

care of this group was compared with that of a sample of women, matched for age, gravidity, and location of home, who booked 48 hour admissions to the local GP maternity hospitals. The costs of a normal delivery in the consultant unit were also estimated. The sample of home confinements was necessarily small, since such confinements are now few and scattered. Data about care in the three groups were derived from interviews with midwives and family doctors, and from hospital notes. Private costs were calculated by a questionnaire and visits to non-respondents.

\section{Costs borne by the public purse}

The elements of maternity care are given in table II.

TABLE II-Elements of maternity care borne by the public purse

\begin{tabular}{|c|c|}
\hline Home delivery & Hospital delivery \\
\hline \multicolumn{2}{|c|}{ Antenatal period } \\
\hline $\begin{array}{l}\text { Attendances at GP antenatal clinic } \\
\text { and parentcraft sessions }\end{array}$ & $\begin{array}{l}\text { Attendances at GP antenatal and } \\
\text { hospital clinics and parentcraft } \\
\text { sessions }\end{array}$ \\
\hline $\begin{array}{l}\text { Visits by community midwife } \\
\text { Blood tests }\end{array}$ & $\begin{array}{l}\text { Visits by community midwife } \\
\text { Blood tests }\end{array}$ \\
\hline \multicolumn{2}{|c|}{ Delivery } \\
\hline $\begin{array}{l}\text { Attendance at birth by midwife and } \\
\text { doctor }\end{array}$ & Ambulance and hospital costs \\
\hline $\begin{array}{l}\text { Probability of transfer } \times \text { cost of } \\
\text { transfer }\end{array}$ & $\begin{array}{l}\text { Attendance at birth by doctor } \\
\text { Probability of transfer } \times \text { cost of } \\
\text { transfer (GP unit only) }\end{array}$ \\
\hline \multicolumn{2}{|c|}{$\begin{array}{lc}\text { sits by midwife and doctor } & \text { Postnatal period } \\
\text { sits to doctor } & \text { Visits by midwife and doctor } \\
\text { Visits to doctor }\end{array}$} \\
\hline
\end{tabular}

\section{ANTENATAL PERIOD}

Attendances at antenatal or parentcraft sessions by the three groups differed little. The home delivery group reported to their doctor, on average, in the 14th week of their pregnancy and attended antenatal clinics at their family doctors' surgeries. The hospital groups reported in the 12 th week and attended on average one extra antenatal clinic. The GP hospital group attended two hospital clinics instead of two at their doctors' surgeries. The consultant unit group attended both types of clinics. In some cases most antenatal care was 
given at the hospital, but usually more family doctor clinics were attended than hospital clinics. The home group received an average of 7.5 antenatal visits from a community midwife, the hospital group two.

\section{DELIVERY}

The cost of 48-hour hospital admissions can be estimated from the cost returns of the two GP maternity units that are separately costed. Costing deliveries that are expected to be normal in a consultant unit is rather more complex, since normal deliveries must be separated from the more costly abnormal deliveries. Since the consultant unit shares a hospital wing with a GP unit, the differences between the two units were estimated, and the costs apportioned accordingly. About a quarter of the women in the hospital groups went to hospital by ambulance (mean: one-mile trip for the GP units and two-mile trip for the consultant unit).

The home delivery group were attended by one or more community midwives, from the onset of labour until an hour or so after birth. The number of midwife-hours spent at a birth ranged from one to 14, (mean six). Ninety-five per cent confidence limits for the mean were 4.5-7.5. For all groups, the doctor was called by the midwife only if she thought his presence was necessary. There was no difference between the groups. For the home delivery and the GP hospital groups the full maternity allowance would be paid to the family doctor. For the consultant unit group, this allowance would be reduced by $£ 5.95$. The hospital costs differed between GP and consultant units.

The proportion transferred from the booked care to a different form of care, either during labour, on account of difficulties, or before, because labour was overdue, was greater for the home group, of whom three were transferred to hospital because they were overdue and two were transferred during labour. Of the GP hospital group, two were transferred to the consultant obstetric unit during labour. This difference between the transfer rates was not statistically significant. If the problems that caused the transfers had occurred to patients booked for the consultant unit (or who were already there) they would have had the same effect-namely, additional days' stay in the consultant unit.

\section{POSTNATAL PERIOD}

The standard pattern of postnatal care by community midwives applied to all groups. The mean number of visits to members of the hospital groups was eight, to the home group 13.

\section{Costs borne by the family}

The costs of a confinement that are borne by the family consist chiefly in the value of days taken off work by the husband. Other factors are visits by additional helpers, the cost of travel to and from hospital, and extra washing and heating for home confinements. All

TABLE III-Results of home costs questionnaire. Number of cases in parentheses

\begin{tabular}{|c|c|c|c|c|c|c|c|}
\hline \multirow{3}{*}{$\begin{array}{l}\text { Mean number of days taken } \\
\text { off work by husband } \\
\text { Annual leave }\end{array}$} & \multirow{3}{*}{$\begin{array}{l}\mathrm{a} \\
\mathrm{b} \\
\mathrm{a} \\
\mathrm{b}\end{array}$} & \multicolumn{2}{|c|}{$\begin{array}{l}\text { Home birth } \\
\text { (17) }\end{array}$} & \multicolumn{2}{|c|}{$\underset{\text { birth }}{\text { GP unit }}$} & \multicolumn{2}{|c|}{$\begin{array}{c}\text { Consultant } \\
\text { unit } \\
\text { (two-day } \\
\text { stay) } \\
(29)\end{array}$} \\
\hline & & $6 \cdot 4$ & (16) & $4 \cdot 5$ & $(25)$ & 11 & (21) \\
\hline & & $\begin{array}{l}6 \\
6 \cdot 5 \\
5\end{array}$ & (13) & $\begin{array}{l}4 \\
5 \cdot 3 \\
2 \cdot 5\end{array}$ & (13) & $\begin{array}{l}8 \\
8 \cdot 4 \\
2 \cdot 75\end{array}$ & $(10)$ \\
\hline Special leave with pay & a & 2 & (1) & 1 & (2) & 7 & (1) \\
\hline Unpaid leave & & $\begin{array}{l}0 \cdot 1 \\
7 \cdot 5\end{array}$ & (2) & $\begin{array}{l}0 \cdot 1 \\
3\end{array}$ & $(10)$ & $\begin{array}{l}0.25 \\
14.5\end{array}$ & (10) \\
\hline $\begin{array}{l}\text { Mean number of days help } \\
\text { given by someone else }\end{array}$ & 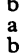 & $\begin{array}{l}0 \cdot 9 \\
4 \cdot 7 \\
2 \cdot 5\end{array}$ & (9) & $\begin{array}{l}1 \cdot 4 \\
7 \\
3\end{array}$ & (12) & $\begin{array}{l}5 \\
9 \\
5 \cdot 3\end{array}$ & (17) \\
\hline $\begin{array}{l}\text { Necessitating time off } \\
\text { work }\end{array}$ & $\begin{array}{l}\mathrm{a} \\
\mathrm{b}\end{array}$ & 二 & 二 & $\begin{array}{l}9 \cdot 3 \\
2\end{array}$ & (6) & $\begin{array}{l}6.5 \\
0.9\end{array}$ & (4) \\
\hline Helper not in employment & & $4 \cdot 7$ & (9) & $4 \cdot 6$ & (6) & $9 \cdot 8$ & (13) \\
\hline $\begin{array}{l}\text { Mean payment (or cost of } \\
\text { gift) for help }\end{array}$ & a & $\begin{array}{l}2 \cdot 3 \\
£ 5 \cdot 30 \\
£ 1 \cdot 25\end{array}$ & (4) & 1 & - & $\begin{array}{l}4.4 \\
£ 5 \cdot 60 \\
£ 1 \cdot 75\end{array}$ & (9) \\
\hline
\end{tabular}

Rows ' $a$ ' = Means over the number of cases where the reply was not "zero." Rows ' $\mathrm{b}$ ' = Means over all cases. except the last two were estimated from responses to a questionnaire* posted to all members of each group. Seventeen of the home confinement group of 22 replied. The response rates of the other groups were similar, but, since the populations from which the samples had been drawn were large, questionnaires were sent to an extra 60 women, 30 from the GP units and 30 from the consultant unit (twoday stay). The final response was home confinements 17, GP units 28, and consultant unit 29 . A check on type and location of house as an index of social and economic class, showed a satisfactory mix of respondents. Table III shows the information gathered from analysis of the questionnaire. Mean values are given, since the spreads of the distributions were low, with at least two-thirds of observations being within 1.5 days of the modes.

In $75 \%$ of cases the "other helper" was the woman's mother; the remaining $25 \%$ were from a wide range of relatives and friends.

Private travelling costs were not high, since only five helpers came from more than a few miles away. The cost of private transport to hospital, and for visiting, was estimated, as was the cost of extra heating and washing.

Extra private travel for the hospital groups was estimated at an average of 12 miles plus 16 miles a day inpatient stay for the consultant unit group, and 8 miles plus 11 miles a day for the GP unit group.

\section{Attributing costs}

PUBLIC PURSE COSTS

\section{Visits from community midwives}

From the diaries of a sample of six midwives in Dudley (Dudley AHA employs 30 community midwives) the average time spent on each element of the midwives' job content was estimated. When the resulting figures were multiplied by the totals of each element, as given for 1977 in the midwifery return to the AHA, the sum of the hours derived matched almost exactly the years' available hours. The average number of hours per visit, including travelling, were 1·15. The mean hourly cost to the employing authority of a community midwife was $£ 2 \cdot 28$, to which 13 p to cover overheads (various items of equipment, radios, etc) has been added. The cost of the journey associated with each visit was computed by dividing the mean car allowance paid by the mean number of job elements entailing travel. The resulting figure was $27 \mathrm{p}$. A visit cost, therefore, $£ 3 \cdot 04$.

\section{Ambulance cost}

The cost of the West Midlands ambulance service in 1977 was $£ 1 \cdot 20$ a mile.

\section{Hospital costs}

Forms cost 1 and cost 2 of the cost statements held by the regional health authority for the GP hospitals yield the average cost per outpatient visit and per inpatient day. It was necessary first to reallocate costs between outpatients and inpatients, since for some accounting reason nursing costs had been loaded excessively on outpatients, and then to adjust average cost upwards, since average length of stay was four days, and a two-day stay, of which time in labour was therefore a greater proportion, would be more expensive per day. The resulting figure for a two-day stay, plus two outpatient visits, was $£ 104 \cdot 50$.

The overall cost of the consultant maternity unit, on the basis of staffing levels relative to the rest of its parent hospital, was $£ 59$ per inpatient day, whereas the cost of the GP maternity beds (excluding payments to doctors) was $£ 39$. Costs peak around delivery, and the shorter the total stay, the more significant this effect becomes. For a normal delivery, however, fewer resources are needed than for an abnormal delivery; in the labour ward about half, and in the postnatal ward rather less than that. On the basis of the average number of births a day, the average length of time in the labour ward, and the observed ratio of normal to abnormal deliveries costs may be allocated between normal and abnormal deliveries. This procedure yields a cost of $£ 106$ for inpatient care, to which must be added $£ 15$ for the mean four outpatient attendances. $\dagger$ Total $£ 121$.

*Available on request from J A S.

†The number of hospital clinics attended does not affect payments to the family doctor for antenatal care. 


\section{Midwife attendance cost}

On average, 1.125 midwives attended each home birth for an average of six hours each. The hourly rate was augmented by $14 \%$ to allow for the extra payments for those hours outside the normal working day. Travel payments as for 1.125 visits were added. Total $£ 15 \cdot 85$.

\section{Probability of transfer}

Of the home group, two were transferred to a GP hospital for a total of 10 days, and three were transferred to an obstetrics unit for a total of 21 days, about 60 ambulance miles. Total cost was $£ 1186$, which yields a figure of $£ 54$ per member of the group. Of the GP hospital group, two were transferred to an obstetric unit for eight days at an extra cost of $£ 304, £ 13.82$ per group member. The same figure, minus ambulance cost, should be imputed to the consultant unit group- $€ 12.50$ per group member.

\section{Lost tax yield}

Lost tax yield arises from the days taken off work by husband or other helper (see below). The figures are $£ 25$ and $£ 18$.

\section{COSTS BORNE BY THE FAMILY (TABLE IV)}

Days spent at home by the husband were counted at the average male wage, ${ }^{10}$ adjusted for the average unemployment level. Whether the leave was taken as part of annual holiday or as extra unpaid leave allowance was made for lost income tax and social security payment, which have already been counted as a public sector cost (see below). The figures estimated were $£ 71$ and $£ 46$. Days off work by a female relative were counted in the same way, the mean female wage being $£ 50$.

Travelling costs were estimated at $12 \mathrm{p}$ a mile, extra washing and heating for the home delivery group at $£ 2 \cdot 15$.

TABLE IV-Average cost per birth of antenatal, confinement, and postnatal care

\begin{tabular}{|c|c|c|c|}
\hline & $\begin{array}{c}\text { Home } \\
\text { confinement }\end{array}$ & $\begin{array}{c}\text { GP } \\
\text { hospital }\end{array}$ & $\begin{array}{c}\begin{array}{c}\text { Consultant } \\
\text { unit }\end{array} \\
\end{array}$ \\
\hline $\begin{array}{l}\text { Public sector } \\
\text { Antenatal home visits by midwife .. }\end{array}$ & $22 \cdot 8$ & 6.08 & 6.08 \\
\hline $\begin{array}{l}\text { Antenatal home visits by midwie } \\
\text { Community midwife attendance at }\end{array}$ & 248 & 0.08 & \\
\hline $\begin{array}{l}\text { antenatal lclinic } \\
\text { Hospital/delivery (including " }\end{array}$ & $3 \cdot 0$ & $3 \cdot 0$ & 1.50 \\
\hline $\begin{array}{l}\text { ambulance transport) } \\
\text { Allowance for transfer or prolonged }\end{array}$ & $15 \cdot 85$ & $106 \cdot 70$ & $123 \cdot 40$ \\
\hline $\begin{array}{l}\text { Allowance for transfer or prolonged } \\
\text { stay }\end{array}$ & $49 \cdot 77$ & $13 \cdot 82$ & $12 \cdot 42$ \\
\hline $\begin{array}{l}\text { Postnatal visits } \\
\text { Payments to family doctor } \ldots\end{array}$ & $\begin{array}{l}39 \cdot 52 \\
35.75\end{array}$ & $\begin{array}{l}24 \cdot 32 \\
35 \cdot 75\end{array}$ & $\begin{array}{l}24 \cdot 32 \\
30 \cdot 00\end{array}$ \\
\hline Lost tax yield $\quad \ldots$ & 30.00 & 27.20 & $43 \cdot 30$ \\
\hline $\begin{array}{l}\text { Family costs } \\
\text { Lost wages holiday ... }\end{array}$ & $55 \cdot 00$ & $49 \cdot 60$ & \\
\hline $\begin{array}{l}\text { Payment for services } \\
\text { Transport, including visiting by }\end{array}$ & 1.25 & - & 1.75 \\
\hline $\begin{array}{l}\text { Transport, including visiting by } \\
\text { husband } \\
.\end{array}$ & $2 \cdot 27^{*}$ & $4 \cdot 20$ & $8 \cdot 40$ \\
\hline $\begin{array}{l}\text { Power }{ }_{\text {Subtotal-public sector }} \\
\text {. }\end{array}$ & $\begin{array}{r}2.15 \\
196.69\end{array}$ & $21 \overline{6 \cdot 87}$ & $24 \overline{1 \cdot 02}$ \\
\hline Subtotal-family costs. & $60 \cdot 67$ & $53 \cdot 80$ & $89 \cdot 15$ \\
\hline Total & $257 \cdot 36$ & $270 \cdot 67$ & $330 \cdot 17$ \\
\hline
\end{tabular}

*Visiting those transferred to hospital.

\section{Discussion}

This costing study has shown that (1) public sector costs are about $10 \%$ higher for a consultant unit confinement than for a GP hospital confinement, which are in turn about $10 \%$ higher than the costs of a home confinement; (2) family costs appear higher for a home confinement than a GP hospital confinement, but lower than for a consultant unit confinement; and (3) family costs are, in general, about $30 \%$ of public sector costs.

The lower family cost of a home confinement compared with a consultant unit confinement was in accordance with expectations - since one of the main arguments put forward for a home confinement is to minimise disturbance at home. The lower family costs of a GP hospital confinement are inexplicable in these terms, and it is therefore impossible to draw a general conclusion about relative family costs of home and hospital confinement.

The finding that a home confinement is, overall, cheaper by only about 5\% than a GP hospital confinement differs from that of Ferster and Pethybridge. ${ }^{9}$ For what purposes, however, can such conclusions be used, and when must adjustments be made to work carried out on an average cost basis? The first, and crudest, purpose is to counter equally crude claims of a cost advantage either way. Secondly, the marginal cost of maternity hospital care now is in general lower than average cost ; in other words, the capacity of maternity hospitals is such that a small increase in their work load that might, for example, be caused by the total withdrawal of the home delivery service, would not entail the employment of extra staff or the opening of new wards. Similarly, home deliveries are such a small proportion of the work of community midwives that it is difficult to envisage that even doubling their numbers would affect the total level of employment. At present the relative average costs of home and hospital deliveries do not reflect savings that could be made if either method were to decline.

The consultant unit was only $15 \%$ more expensive than the GP hospital. Given the difficulty of separating the costs of normal from abnormal deliveries within the consultant unit, it would not be possible to conclude that if (for the sake of argument only) a thousand births annually were transferred from the GP hospital to the consultant unit, an extra cost of $£ 16000$ would be incurred. Indeed, it is possible to argue that staffing economies would make the marginal public sector cost of normal deliveries in the consultant unit considerably lower; against this it would be necessary to set increased private travel cost.

When the present shrinkage of existing maternity services has achieved a fit of overall capacity to demand-or if the dramatic 1979 increase in the birth rate continues-our information may help in planning the range of services to be offered. Average cost figures need to be interpreted with care in an area where precautionary capacity is necessary, and the clearest characteristics of the sample of home confinements studied was the unforeseen necessity of additional services-whether a second midwife, doctor, or hospital admission.

Although the difference between the transfer rates from home to hospital, and from GP hospital to consultant obstetric unit, was not statistically significant, the transfers would be amenable to a different interpretation if GP unit and consultant unit were organically linked. Then one would be comparing a transfer rate of $5 / 22$ with a transfer rate of zero. Clearly, therefore, any acceptable strategy of maternity care that includes home confinements must make appropriate provision for lastminute transfers to hospital.

I thank the chairman and officers of Dudley Area Health Authority, the nursing officers and midwives of the Dudley Midwifery Service, and Mr R McLean, consultant obstetrician and gynaecologist, for their co-operation and help in this study.

\section{References}

1 Central Statistical Office, Social Trends, London, HMSO, 1977.

${ }^{2}$ Department of Health and Social Security, Domiciliary Midwifery and Maternity Bed Needs, London, HMSO, 1970.

${ }^{3}$ Fedrick, J, and Butler, N R, British Medical fournal, 1978, 1, 763.

4 Barron, S L, Thomson, and A M, Philips, P R, British fournal of Obstetrics and Gynaecology, 1977, 84, 401 .

5 British Medical fournal, 1976, 1, 55.

6 Tew, M, New Society, 20 January 1977, 120.

${ }^{7}$ Kitzinger, S, and Davis, J, (editors), The Place of Birth, London, Oxford University Press, 1978.

8 Goldthorp, W O, and Richman, J, Practitioner, 1974, 212, 845.

${ }^{9}$ Ferster, G, and Pethybridge, R J, The Hospital and Health Services Review, 1973, 243.

10 Department of Employment Gazette, April 1979, Table 126. 